vagotomy and drainage that they see no need to look for better results, ${ }^{10}$ but we agree with Amdrup et al. ${ }^{11}$ that we should try to eliminate all tiresome side effects. The safety of P.G.V. has been shown by Johnston, ${ }^{12}$ who studied 5257 cases drawn from 40 international centres and showed a mortality of only $0.3 \%$. We had no deaths in either group in this trial and have not seen the lesser curve necrosis which has been described.

The key factor to be considered about any new operation for duodenal ulcer must be the recurrent ulcer rate, not just in the duodenum but also in the stomach. We have had just one proved recurrence in each group-a rate of $2 \%$, which is quite acceptable. Kronborg and Madsen ${ }^{6}$ in a very similar trial had a rate of $22 \%$, which is totally unacceptable. Why should there be this great difference? We believe that not all surgeons are doing the same operation. We have preserved the innervation to a measured $6 \mathrm{~cm}$ of the distal lesser curve, sometimes preserving only one of the terminal branches of the anterior nerve of Latarjet. Kronborg located the junction of the corpus and the antrum using a $\mathrm{pH}$ probe or by staining the mucosa with Congo red through a small gastrotomy. He found that the junction varied between 4 and $17 \mathrm{~cm}$ from the pylorus, with a mean of $8.6 \mathrm{~cm}$. It seems, therefore, that he preserved more antral innervation than we have done, which may explain our different recurrence rates. Amdrup et al. ${ }^{11}$ have recently reported two gastric ulcers and three suspected but unproved duodenal recurrences among 108 patients followed for a minimum of two and a maximum of four years.

The most striking result of our trial was the virtual elimination of dumping in the P.G.V. group, a result that we had expected since uncontrolled gastric emptying is prevented. Not surprisingly, episodic diarrhoea was also almost eliminated; most of the diarrhoea in both groups was linked to dumping, and we have previously found that this is the type of diarrhoea that is not eliminated when truncal is replaced by selective vagotomy. Our finding of retrograde intussusception in two patients was surprising but must be regarded as further evidence against drainage.

Nutritionally the patients who underwent P.G.V. seemed to fare better, but we have found that clinical status bears no relation to weight loss or gain (unpublished data).

Bile vomiting is related to regurgitation of duodenal content into the stomach, and this readily occurs after gastrojejunostomy or pyloroplasty but is rare after P.G.V. with an intact pylorus.
Two symptoms that we feared might occur in this study were flatulence and vomiting of food due to delay in gastric emptying. That this is not a problem in practice is indicated by our finding that these symptoms were no commoner after P.G.V. than in our control group of patients with no known gastrointestinal disorder. Though we had one patient with troublesome food vomiting we did not need to reoperate, and stasis did not prove a problem in this series. Amdrup et al. ${ }^{11}$ reoperated for stasis in two of their 108 cases while Johnston ${ }^{12}$ reported a reoperation rate of $0.6 \%$ on this account in his 5257 cases.

Our results in this trial must be compared with those of Kronborg and Madsen, ${ }^{6}$ who have reported the only other random controlled trial. The design of their trial was remarkably similar: 50 patients who underwent P.G.V. were compared with 50 undergoing selective vagotomy and pyloroplasty. Ninety-six patients were followed for one year. They found significantly less dumping, diarrhoea, and epigastric fullness in patients who had had P.G.V., and when the recurrent ulcers were excluded there were significantly better overall clinical results.

From our results we conclude that P.G.V. is a safe operation in which side effects are almost eliminated. There is a low recurrence rate in the first two years, but more time is needed to give a definite answer about the ultimate recurrence rate. As yet nothing indicates that it will prove to be any higher than that of other forms of vagotomy and drainage. Should it do so later little or no harm will have been done as we found no difference in the proportion of Visick 1 gradings between our P.G.V. patients and our controls. The technique is not difficult to learn, and P.G.V. without drainage should be more widely used in the treatment of duodenal ulcer.

\section{References}

${ }^{1}$ Kennedy, T., et al., British fournal of Surgery, 1973, 60, 944.

${ }^{2}$ Kennedy, T., et al., British Fournal of Surgery, 1973, 60, 949.

3 Johnston, D., and Wilkinson, A. R., British Fournal of Surgery, 1970, 57, 289.

4 Amdrup, E., and Jensen, H.-E., Gastroenterology, 1970, 59, 522.

5 Wastell, C., et al., British Medical fournal, 1972, 1, 28.

6 Kronborg, O., and Madsen, P., personal communication, 1975.

Siegel, S., Non-Parametric Statistics for the Behavioural Sciences, New York, McGraw-Hill, 1956.

8 Burns, G. P., and Menzies, T., British fournal of Surgery, 1966, 53, 433.

9 Hollander, F., Gastroenterology, 1948, 11, 419.

10 Kennedy, F., et al., British Medical fournal, 1973, $2,71$.

12 Johnston, D., personal communication, 1975.

\title{
Psychosocial Effects of Disaster: Birth Rate in Aberfan
}

\author{
R. M. WILLIAMS, C. MURRAY PARKES
}

British Medical fournal, 1975, 2, 303-304

\section{Summary}

An increased birth rate occurred in Aberfan during the five years after the disaster there in 1966. It was not confined to the bereaved parents.

\section{Introduction}

On 21 October 1966, in the Welsh mining village of Aberfan

St. Tydfil's Hospital, Merthyr Tydfil, Glamorgan CF47 0SJ R. M. WILLIAMS, M.B., M.F.C.M., District Community Physician

Tavistock Institute of Human Relations, London NW3 5 BA C. MURRAY PARKES, M.D., F.R.C.PSYCH., Social Psychiatrist

and its companion village Merthyr Vale, 116 children and 28 adults were killed when an avalanche of coal slurry engulfed the village primary school and several houses. Some of the psychological damage produced was reported by Lacey (summariżed by Anthony ${ }^{1}$ ). Using statistics now available from the Registrar of Births and Deaths we have plotted changes in the birth rate during the five years before and after the disaster.

\section{Method}

Birth rate is measured as births per 1000 population. Thus an increase may result from either a rise in the number of births or a fall in the population. The fall in the population of Aberfan due to the disaster would therefore be expected to be associated with a rise in the birth rate even if the number of births remained the same.

In attempting to find whether there was a rise in the birth rate attributable to an increase in births among those of reproductive age it was necessary to exclude from consideration the children who died 
in the disaster. To do this, population estimates from 1967 onward were increased by 116 . On the other hand, the 28 adults who died were included in the population estimates, since many of them would have been of reproductive age. Between the 1961 and 1971 Censuses the population of the Aberfan and Merthyr Vale ward fell from 5459 to 4642 . This was accounted for by ex-migration, since during the same period there was an excess of 219 births over deaths (discounting the 116 child deaths in the disaster). The total number of exmigrations was therefore 920 , or 92 a year. In calculating the yearly population we assumed that this rate of attrition was steady and subtracted from it the excess of births over deaths for each year.

We also calculated the number of children who would have been born in Aberfan and Merthyr Vale had the trend in the birth rate for the years 1962-7 continued. During that period there was a mean decline of 3.6 births a year. The mean number of births a year over the five-year period was 80.6 . Starting from the midpoint of the quinquennium, 1965, and assuming an expected 80.6 births during that year, we subtracted 3.6 births successively year by year.

For comparison we obtained birth rate figures for the other seven wards which, with Aberfan and Merthyr Vale, make up the County Borough of Merthyr Tydfil (population 54530 in 1971).

\section{Results}

The figure shows the changes in birth rate in Aberfan and Merthyr Vale corrected for population change due to the child deaths in 1966, as described above. During 1962-7 the changes in birth rate mirrored those for the rest of the borough, which had a slightly higher overall rate. No effect of the disaster on birth rate would have become apparent until the second half of 1967, and, in fact, there was no significant change during that year. In 1968, however, the birth rate increased sharply from 14.38 per 1000 to 20.80 per 1000 , and it remained above the rate for the rest of the borough until 1972, the last year for which figures are available.

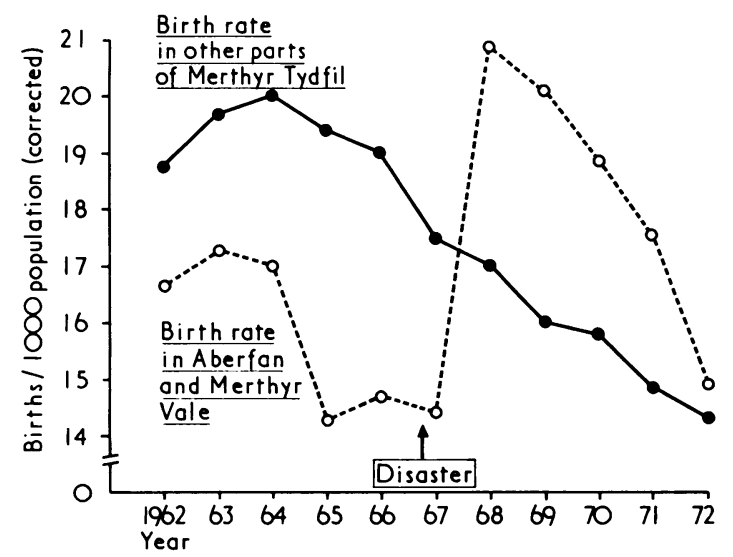

Yearly birth rates in Aberfan and Merthyr Vale ward and other parts of Merthyr Tydfil during 1962-72.

The table gives the number of births which took place each year in Aberfan and Merthyr Vale from 1968 to 1972 compared with the number expected when assuming a linear decline, as explained above. Over the five-year period 445 children were born, 132 more than expected. To find whether this increase was confined to parents who had lost a child in the disaster we compared the birth registers with the death roll. Surprisingly, only 14 pairs of bereaved parents had had one or more further children during 1968-72. Between them, they had given birth to 17 children (three other bereaved families had left the area and could not be traced).

As in the rest of the population, the number of births to bereaved parents reached a peak in 1968 and declined rapidly thereafter. Thus only a small proportion of the increased birth rate in Aberfan after the disaster was attributable to the bereaved parents.
Expected and Actual Numbers of Births in Aberfan and Merthyr Vale

\begin{tabular}{|c|c|c|c|}
\hline Year & $\begin{array}{c}\text { Expected No. } \\
\text { (See Text) }\end{array}$ & Actual No. & $\begin{array}{c}\text { No. to } \\
\text { Bereaved Parents }\end{array}$ \\
\hline $\begin{array}{l}1965 \\
1966 \\
1967 \\
1968 \\
1969 \\
1970 \\
1971 \\
1972\end{array}$ & $\left.\begin{array}{l}80 \cdot 6 \\
77 \cdot 0 \\
73 \cdot 4 \\
69 \cdot 8 \\
66 \cdot 2 \\
62 \cdot 6 \\
59 \cdot 0 \\
55 \cdot 4\end{array}\right\} 313 \cdot 0$ & $\left.\begin{array}{r}74 \\
75 \\
72 \\
103 \\
98 \\
91 \\
83 \\
70\end{array}\right\} 445$ & $\left.\begin{array}{l}3 \\
6 \\
4 \\
3 \\
1 \\
3\end{array}\right\} 17$ \\
\hline
\end{tabular}

\section{Conclusions}

By 1972 the number of children killed in the disaster had been replaced and the birth rate had fallen to near the pre-disaster level. It had not, however, fallen to the level which would have been reached had the decline indicated by pre-disaster figures continued. The increase in births was not confined to the bereaved parents but was spread over the whole population.

Clinical studies have indicated risks to children born to replace a dead child. Cain and Cain ${ }^{2}$ claimed that such children may be overprotected and expected to live up to the idealized memory of their dead sibling, and Paul and Grosser ${ }^{3}$ and Welldon ${ }^{4}$ reported that they may suffer lasting identity problems. These workers independently concluded that such misidentification may even cause schizophrenia in later life, which, if verified, carries important implications for preventive psychiatry. But these studies were based on a few cases referred for psychiatric help and give no indication how great the danger to health may be in the average child-bereaved family. Nor do they tell us anything about children born to parents who have not been bereaved (most in this study).

A common observation in disaster areas is that those who survive are strongly motivated not only to repair the damage but to bring something positive out of the ruins. As Barton put it, "When conditions are favourable, the therapeutic community response sets in motion enough helping behaviour to reduce rapidly the deprivation of the victims of collective stress, thereby restoring the situation to its prior equilibrium. It is possible that the effects will even go beyond that to produce a net improvement, an 'amplified rebound' from disaster ?" 5

In Aberfan and Merthyr Vale the disaster gave rise to a community development programme, which is now viewed as a model. Journalists and others who visit the area find a mature and responsible community, whose morale is probably higher than it has ever been. ${ }^{6}$

In the light of these changes it seems reasonable to conjecture that the increased birth rate in Aberfan and Merthyr Vale observed during the first five years after the disaster was mainly a consequence of a process of biosocial regeneration by couples who had not themselves lost a child. This process cannot bring back the children who died or remove all the scars of bereavement; there are, no doubt, some in the community who have suffered lasting damage. But it does provide grounds for recognizing that psychosocial transitions of this kind are not entirely destructive in their effects when viewed from the perspective of the total community in which they occur.

\section{References}

1 Anthony, E. J., The Child in His Family. New York, Wiley, 1973.

2 Cain, A. C., and Cain, B. S., fournal of the American Academy of Child Psychiatry, 1964, 3, 443.

3 Paul, N. L., and Grosser, G. H., Community Mental Health Fournal, 1965,

4 1, 339. Relldon, R. M. C., Family Process, 1971, 10, 281.

5 Barton, A. H., Communities in Disaster. New York, Doubleday, 1969.

${ }^{6}$ Nossiter, B. D., The Washington Post, 27 May, 1973. 